\title{
A língua portuguesa entre as línguas de Timor-Leste: um estudo de caso numa escola secundária timorense
}

\author{
Portuguese Language among East Timor \\ Languages: A Case Study in a Timorese \\ Secondary School
}

\section{La lengua portuguesa entre los idiomas de Timor Oriental: un estudio de caso en una escuela secundaria timorense}

Rui Ramos ${ }^{1 *}$

*Universidade do Minho (UMinho), Braga / Portugal

rlramos@ie.uminho.pt

http://orcid.org/0000-0001-8700-8301

José do Carmo ${ }^{2 * *}$

**Universidade da Paz (UNPAZ), Díli/ Timor-Leste

jos_carmo@yahoo.com

http://orcid.org/0000-0002-7955-8028

\begin{abstract}
RESUMO: O cenário linguístico timorense é complexo: uma sociedade multilingue e de tradição oral, duas línguas oficiais, um grande número de línguas autóctones ágrafas, um sistema de ensino pobre, fraca formação dos professores, indecisões e contradições na política educativa ao longo do tempo. $\mathrm{Na}$ escola, a língua portuguesa, oficialmente uma das línguas do ensino, não é dominada por todos, competindo frequentemente com o tétum, o indonésio
\end{abstract}

\footnotetext{
${ }^{1}$ Doutor em Linguística, professor do Instituto de Educação da Universidade do Minho, Portugal; investigador do Centro de Investigação em Estudos da Criança e do Centro de Estudos Humanísticos daquela universidade. Entre 2014 e 2015, foi Coordenador-adjunto Científico e Pedagógico do Instituto da Língua Portuguesa da Universidade Nacional Timor Lorosa'e, em Timor-Leste.

${ }^{2}$ Licenciado em Ensino da Língua Portuguesa, professor da Universidade da Paz, TimorLeste.
} 
e línguas locais. Fora das salas de aula, quase desaparece. O presente estudo de caso apresenta os resultados de um inquérito ao domínio de línguas, às perceções e aos hábitos culturais de alunos de uma escola pública timorense, em Díli. Analisa os resultados numa perspetiva dominantemente qualitativa e discute-os, considerando inflexões das práticas culturais no ensino formal. Confirma o cenário multilingue timorense, mas permite questionar uma correlação linear entre área geográfica e língua local, pelo menos para o contexto da capital.

PALAVRAS-CHAVE: língua portuguesa; língua segunda; Timor-Leste; diversidade linguística.

\begin{abstract}
The Timorese linguistic setting is complex: a multilingual society with oral tradition, two official languages, a large number of autochthonous native unwritten languages, a poor educational system, weak teacher training, indecisions and contradictions in educational policy over time. At school, the Portuguese language, which is one of the official teaching languages, is not dominated by all, often competing with Tetum, Indonesian and local languages. Outside the classrooms, it almost disappears. The present case study presents the results of a survey on the language proficiency, on their perceptions and on cultural habits of students in a Timorese public school in Dili. It analyses the results mainly from a qualitative perspective and discusses them, considering the effects of cultural practices in formal education. It confirms the Timorese multilingual scenario, but allows us to question a linear correlation between geographical area and local language, at least for the context of the capital.
\end{abstract}

KEYWORDS: Portuguese language; second language; East-Timor; linguistic diversity.

RESUMEN: El contexto lingüístico timorense es muy complejo: hablamos de una sociedad de tradición oral y multilingüe, con dos idiomas oficiales, una gran cantidad de lenguas nativas sin escritura, un sistema educativo deficiente, una formación débil de los docentes, caracterizada por la indecisión y contradicciones en la política educativa a lo largo del tiempo. En la escuela, el idioma portugués, oficialmente uno de los idiomas de enseñanza, no es dominado por todos, compitiendo a menudo con los idiomas tétum, indonesio y lenguas nativas. Fuera de las aulas, el portugués casi desaparece. Este estudio de caso presenta los resultados de una encuesta sobre el dominio del idioma portugués, incluyendo las percepciones y los hábitos culturales de los alumnos en una escuela pública timorense en Díli, la capital de Timor-Leste. Analiza los resultados desde una perspectiva predominantemente cualitativa y los discute, considerando las inflexiones de las prácticas culturales en la educación formal. Confirma el escenario multilingüe timorense, pero nos permite cuestionar una correlación lineal entre el área geográfica y el idioma local, al menos para el contexto de la capital.

PALABRAS-CLAVE: lengua portuguesa; segunda lengua; Timor-Leste; diversidad lingüística. 


\section{Introdução}

Nos últimos anos, diversos investigadores têm feito descrições, mais ou menos exaustivas, do panorama multilinguístico de Timor-Leste e do seu contexto mais alargado (nomeadamente, HULL, 2002; THOMAZ, 2002; CARVALHO, 2003; CORTE-REAL; BRITO, 2006; TAYLOR-LEECH, 2009, 2012; ALBUQUERQUE, 2010, 2010a, 2011, 2011a, 2012, 2012a, 2013, 2014, 2015, 2015a; BRITO, 2010, 2011; CARNEIRO, 2010; ALMEIDA, 2011; LOURENÇO, 2011; SEVERO, 2011; ALBUQUERQUE; TAYLORLEECH, 2012; FONSECA, OSÓRIO; SANTOS, 2015; CARDOSO, 2017). Alguns deles abordam de modo articulado a questão da descrição linguística e a do ensino das línguas naquele país (ANTUNES, 2003; ALBUQUERQUE, 2010b; TAYLOR-LEECH, 2011; SOARES, 2014; VIEGAS; RAMOS; ANTUNES, 2015; RAMOS, 2016; CAVALCANTE; BRITO, 2016; XIMENES, 2016; INDART, 2017, entre outros). ${ }^{3}$

Thomaz (2002), num texto frequentemente citado, encontrou uma designação feliz e económica para essa realidade e usa-a num título apropriado: "Babel Loro Sa'e". ${ }^{4}$ E Hull descreve da seguinte forma a desconcertante diversidade linguística de toda a região onde Timor-Leste se insere:

[it] presents a bewildering degree of linguistic variety, a phenomenon that impressed and astonished the first European visitors to the area. It is a daunting task to attempt to establish mutual relationships and explore genetic connections for

\footnotetext{
${ }^{3}$ Como regista Geoffrey Hull (1998), nos primeiros séculos de colonização, os portugueses e os holandeses não dedicaram atenção relevante às línguas faladas na ilha de Timor. De acordo com Luís Filipe Thomaz (1982), o mais antigo documento linguístico direto sobre Timor é um glossário de 417 palavras originais de línguas locais, elaborado por um francês, no século XVIII, na sequência de uma visita à ilha em 1772. Hugo Cardoso (2017) assinala que é de 1886 a publicação da primeira obra dedicada à descrição de uma língua timorense; e, na viragem do século XIX para o século XX, foram várias as publicações que se debruçavam sobre o que, hoje, pode chamar-se diversidade linguística. Esta visão diacrónica, da qual se dá esta brevíssima nota, não é explorada no presente estudo, que se centra na contemporaneidade - tanto ao nível da produção científica, quanto ao nível do objeto de estudo.

${ }^{4}$ Obviamente, um jogo entre o nome do país em tétum, Timor Loro Sa'e, e a referência ao episódio bíblico da Torre de Babel.
} 
these hitherto little studied languages, in many respects more dissimilar than similar and for many of which 'Austronesian' is a tentative label rather than an unambiguous classification. (1998, p. 24).

De facto, Timor-Leste situa-se num dos cenários do mundo com maior diversidade linguística e cultural, integrado no que os investigadores designam como Wallacea, uma área geográfica com mais de 250 línguas autóctones e delimitada como se pode ver no mapa seguinte:

FIGURA 1 - "Wallacea”. Licenciado sob GFDL, via Wikimedia Commons

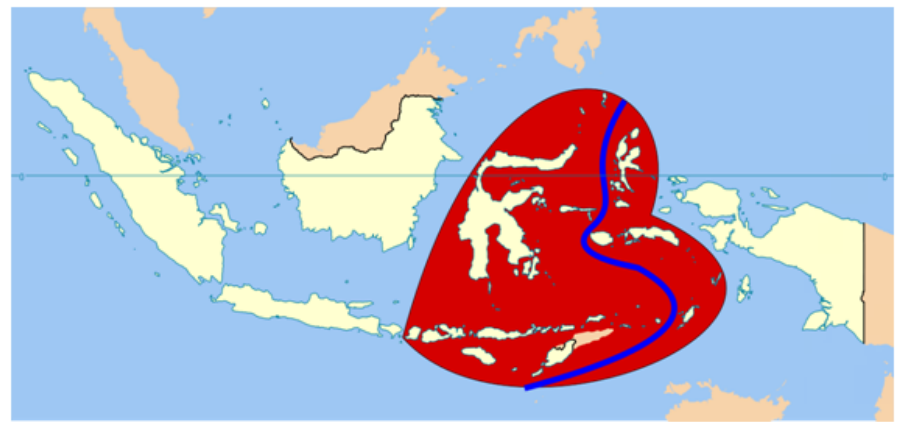

Disponível em: http://commons.wikimedia.org/wiki/File:Indonesia_Wallacea. svg\#/media/File:Indonesia_Wallacea.svg. Acesso em: 23 fev. 2019.

Os linguistas que se interessam por temas integrados na chamada ecolinguística, em particular aqueles que se dedicam ao estudo da ecologia das línguas (RAMOS, 2004, 2004a), a questões de planificação linguística, morte de línguas e inter-relações entre as línguas ao nível da consciência individual e ao nível social em comunidades multilingues (FILL, 2000; HAUGEN, 2001), têm vindo a sublinhar que o multilinguismo não é um mal, não é um castigo, não é uma falha das sociedades, mas uma imensa riqueza, que é importante preservar. Não deixa, contudo, de ser um assunto problemático quando se pretende garantir a coesão nacional, a intercompreensão entre todos os cidadãos do mesmo país, a igualdade de oportunidades, a justiça e a paz social.

Em Timor-Leste, a língua portuguesa foi proibida no tempo da colonização indonésia, mas continuou a ser usada como língua de resistência, nos debates dos líderes políticos, nas atividades clandestinas, nas formas de saudação, etc. 
Depois de 24 anos de ocupação indonésia, Timor-Leste retomou essa língua e consagrou-a na sua Constituição (Artigo 13..$^{\circ}$ ) como língua oficial, ao lado do tétum, com base em aspetos históricos, políticos, culturais, linguísticos, religiosos e económicos. Além disso, a Lei de Bases da Educação (Lei n. ${ }^{\circ}$ 14/2008) determina, no seu artigo 8. ${ }^{\circ}$, que "as línguas de ensino do sistema de ensino timorense são o tétum e o português”. Assim, essa língua funciona na Administração Pública e no ensino e, sobretudo, surge no dia a dia dos cidadãos fortemente mesclada no vocabulário do tétum.

Contudo, é do conhecimento público que nem todos os timorenses dominam adequadamente a língua portuguesa. Mesmo no ensino, como Guimarães e Costa assinalam, "é preciso ressaltar a distância que há entre aquilo que está presente no currículo prescrito, organizado em contextos extraescolares e o que ocorre na sala de aula" (2016, p. 26): ou seja, mesmo nas aulas, nem sempre a língua portuguesa e a língua tétum têm presença exclusiva efetiva, padronizada e operacional. $\mathrm{Na}$ sociedade timorense, elas têm de partilhar o seu espaço com um conjunto alargado de outras línguas.

É razoável pensar que alunos que mantêm com a língua portuguesa um contacto mais assíduo terão mais facilidade em adquirir conhecimentos e em atingir os objetivos educativos mais facilmente do que aqueles que com ela só têm contacto no período das aulas. Acresce que, de um modo geral, as aulas nos vários ciclos e níveis de ensino em Timor-Leste se fundamentam em atividades repetitivas, largamente dependentes de exercícios de memorização, e são dominantemente expositivas, sendo os professores fortemente dependentes de manuais escolares, que seguem religiosamente. Se não por outros, pelo menos por esse motivo seria muito útil que os estudantes timorenses tivessem contacto no seu meio familiar ou nos seus círculos de amigos com a língua portuguesa, língua cooficial (a par do tétum), língua de prestígio social, língua de contacto internacional e língua mais equipada para o uso em sociedades como aquela em que a sociedade timorense está rapidamente a transformar-se (pelo menos, os estratos mais urbanos dessa sociedade) do que as línguas locais, e mais disponível para o pensamento abstrato.

\section{Mapa linguístico de Timor-Leste}

Segundo Geoffrey Hull (2002), o mapa linguístico de Timor-Leste apresenta dezesseis línguas autóctones, sendo inseridas em dois grandes 
grupos. Doze são de origem austronésia: tétum, habun, kawaimina, idalaka, galoli, wetar, bekais, dawan, mambai, kemak, tocodede, lovaia - sendo que o wetar de Ataúro, a pequena ilha situada frente a Díli, tem, nesse território de 140 quilómetros quadrados, menos de oito mil habitantes e seis povoações, mas diferencia-se em três dialetos distintos (rahesuk, resuk, raklungu); as restantes quatro são de origem papua: makasae, makalero, bunak e fataluco. A diversidade linguística motivou o surgimento de uma língua que os falantes de diferentes grupos étnicos usam para comunicarem entre si. Essa língua é o chamado tétum-praça (o dialeto de Díli).

O facto de se falar em "mapa linguístico" sugere que há uma relação forte entre nascer e viver num determinado território ou numa certa zona do país e dominar uma língua, frequentemente entendida como a língua materna dos habitantes. Tal assunção é natural e decorre da experiência prática das pessoas.

Assim, é normal esperar que um natural de Oecussi ou um de Lospalos, por exemplo, tenham o baiqueno ou o fataluco como língua materna, respetivamente. Da mesma forma, será legítimo esperar que um nativo de Díli assuma o tétum (na sua variante tétum-praça) como língua materna.

FIGURA 2 - Mapa linguístico de Timor-Leste (Ethnologue)

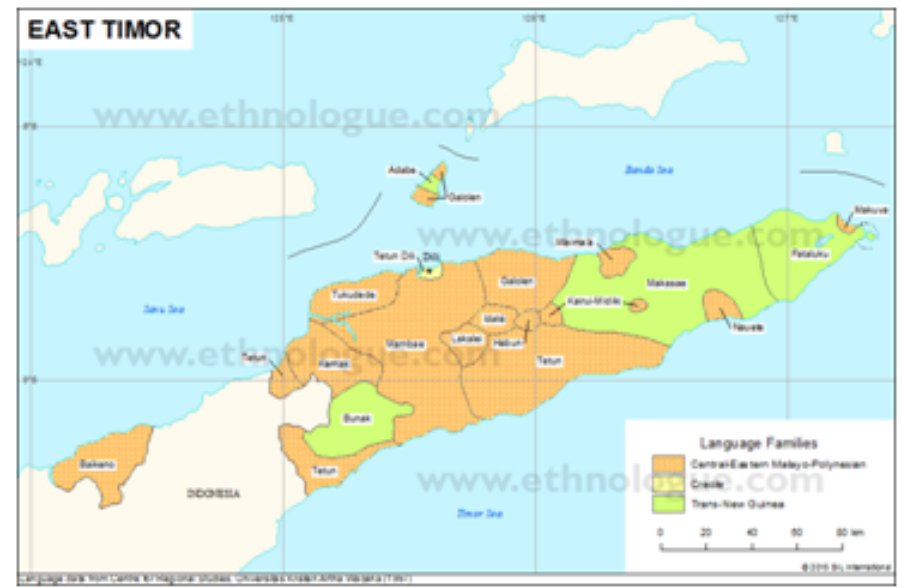




\section{Objetivos e metodologia}

O objetivo do presente artigo é o de contribuir para a discussão sobre a realidade linguística timorense contemporânea, em particular sobre o papel da língua portuguesa. Para o efeito, apresenta e discute dados empíricos recolhidos, através de inquérito, num estudo mais vasto acerca das perceções sobre as línguas, o seu uso contextualizado e o sucesso escolar dos informantes (CARMO, 2015). Trata-se de um estudo de caso, circunscrito e limitado, mas os dados obtidos não deixam de ser relevantes e propiciadores de reflexão.

O estudo em causa contou com a colaboração de alunos de uma turma de Ciências Sociais e Humanas (CSH) e de outra de Ciências e Tecnologia (CT), do 11. ${ }^{\circ}$ ano, da Escola Secundária Nicolau Lobato, em Díli, num total de 43 informantes, em 2015, que aceitaram responder a um inquérito sobre o domínio de línguas, as perceções e os hábitos culturais (linguísticos) de cada um. No total, a turma CSH tem 30 alunos: 18 rapazes e 12 raparigas; a turma CT tem 28 alunos: 15 rapazes e 13 raparigas. As idades variam entre 15 e 18 anos. $\mathrm{O}$ inquérito foi redigido em língua portuguesa e todo o contacto com os alunos foi feito nesta língua, ainda que tenha sido feito por um timorense que domina várias línguas locais.

Neste texto, apresentam-se alguns dos dados mais salientes e interessantes resultantes desse inquérito.

\section{Dados do inquérito}

Entre os elementos de informação mais relevantes do inquérito efetuado, o que se prende com a identificação da língua materna dos inquiridos, a sua proveniência geográfica e o domínio de línguas no seu contexto familiar apresenta resultados que importa expor e discutir.

4.1. Uma das perguntas era "Qual a sua língua materna (LM)?" Com ela, pretendia-se saber quais e qual o número de LM faladas nas duas turmas inquiridas e tentar identificar potenciais focos de atrito e interferência entre línguas locais e a língua portuguesa. A Tabela 1 e o Gráfico 1, abaixo, mostram sumariamente as respostas a esta questão: 
TABELA 1 - Língua materna dos inquiridos

\begin{tabular}{l|c|c}
\hline \multicolumn{3}{c}{ Língua materna dos inquiridos } \\
\hline Mambae & Frequência & Percentagem (\%) \\
\hline Kemak & 13 & 30.23 \\
\hline Baiqueno & 12 & 27.91 \\
\hline Bunak e kemak & 5 & 11.63 \\
\hline Tocodede & 5 & 11.63 \\
\hline Tétum térik & 2 & 4.65 \\
\hline Tétum térik, tétum & 1 & 2.33 \\
\hline Tocodede e baiqueno & 1 & 2.33 \\
\hline Tétum e fataluco & 3 & 6.98 \\
\hline Total & 1 & 2.33 \\
\hline
\end{tabular}

GRÁFICO 1 - Língua materna dos inquiridos

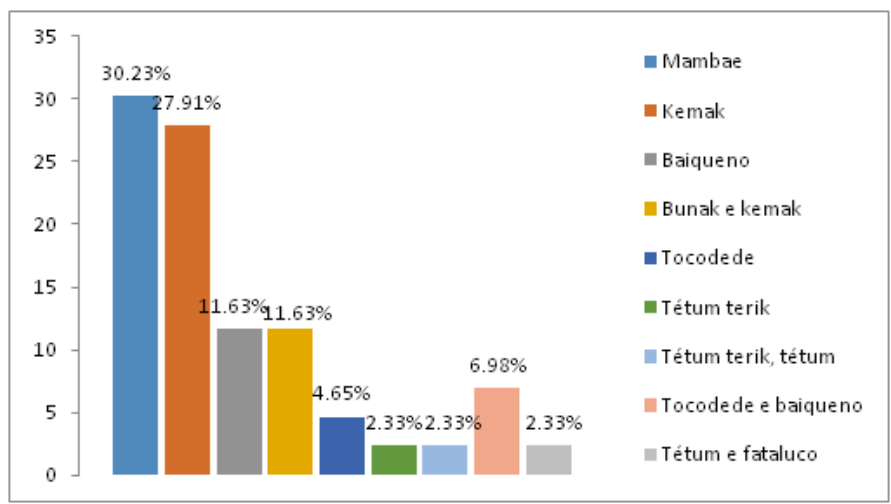

\subsection{A segunda pergunta era "Qual é o distrito" em que nasceu?"}

Esta pergunta pretendia identificar o município de origem de cada informante, essencialmente para poder traçar cenários explicativos quanto à identificação das LM respetivas. A seguir, apresentam-se os valores obtidos na Tabela 2 e no Gráfico 2:

\footnotetext{
${ }^{5}$ Após a realização do estudo original (CARMO, 2015), do qual este texto recolhe dados relevantes, a designação "distrito" foi substituída por "município" como unidade de administração do território.
} 
TABELA 2 - Municípios onde os inquiridos nasceram

\begin{tabular}{l|c|c}
\hline \multicolumn{3}{c}{ Municípios onde os inquiridos nasceram } \\
\hline Município & Frequência & Percentagem (\%) \\
\hline Díli & 15 & 34.88 \\
\hline Bobonaro & 8 & 18.60 \\
\hline Ermera & 7 & 16.28 \\
\hline Oe-cussi & 7 & 16.28 \\
\hline Liquiçá & 2 & 4.65 \\
\hline Suai & 1 & 2.33 \\
\hline Manatuto/Soibada & 1 & 2.33 \\
\hline Lospalos & 2 & 4.65 \\
\hline Total & $\mathbf{4 3}$ & $\mathbf{1 0 0}$ \\
\hline
\end{tabular}

GRÁFICO 2 - Municípios onde os inquiridos nasceram

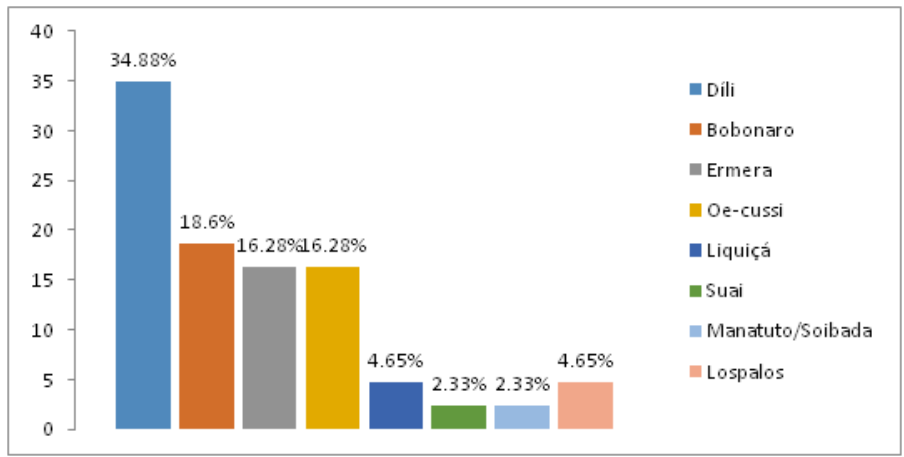

\subsection{A pergunta seguinte foi "Há quanto tempo vive em Díli?"}

$\mathrm{Na}$ sequência das perguntas, esta pretendia identificar o número de estudantes nascidos fora da capital e visava perceber se estes eram habitantes recentes ou de longa data de Díli. 
TABELA 3 - Tempo de vida em Díli

\begin{tabular}{c|c|c}
\hline \multicolumn{3}{|c}{ Há quanto tempo vive em Díli } \\
\hline Anos & Frequência & Percentagem (\%) \\
\hline 18 & 2 & 4,65 \\
\hline 16 & 8 & 18,60 \\
\hline 15 & 5 & 11,63 \\
\hline 11 & 12 & 27,91 \\
\hline 8 & 4 & 9,30 \\
\hline 7 & 6 & 13,95 \\
\hline 5 & 2 & 4,65 \\
\hline 3 & 4 & 9,30 \\
\hline Total & $\mathbf{4 3}$ & $\mathbf{1 0 0}$ \\
\hline
\end{tabular}

GRÁFICO 3 - Tempo de vida em Díli

30
25
20
15
10
5
0

\subsection{Seguiu-se a pergunta "Com quem vive?"}

Com esta questão, pretendia-se conhecer quais são as pessoas com quem o aluno vive, para perceber qual o seu ambiente linguístico familiar. Os resultados recolhidos são apresentados na Tabela e no Gráfico seguintes: 
TABELA 4 - As pessoas que vivem com o aluno

\begin{tabular}{l|c|c}
\hline \multicolumn{3}{c}{ As pessoas que vivem com aluno } \\
\hline \multicolumn{1}{c|}{ Pessoas } & Frequência & Percentagem (\%) \\
\hline Irmãos & 24 & 55,81 \\
\hline Tios e primos & 9 & 20,93 \\
\hline Pais e irmãos & 8 & 18.60 \\
\hline Avós e irmãs & 2 & 4,65 \\
\hline Total & $\mathbf{4 3}$ & $\mathbf{1 0 0}$ \\
\hline
\end{tabular}

GRÁFICO 4 - As pessoas que vivem com o aluno

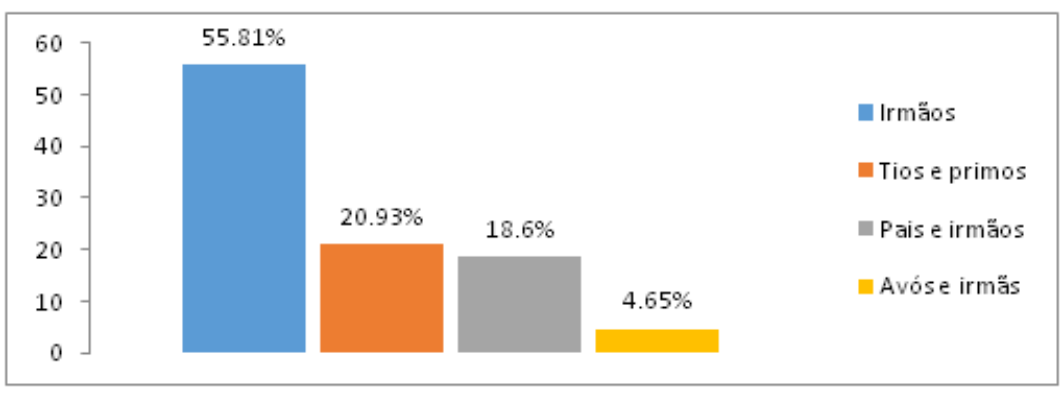

4.5. Finalmente, para o presente estudo, apresentam-se os resultados da pergunta “Que línguas falam as pessoas com quem vive?”.

Esta questão pretendia identificar o número de línguas que falam as pessoas com quem o aluno vive para, de novo, perceber qual o seu ambiente linguístico familiar. A seguir, apresenta-se nos quadros os resultados obtidos: 
TABELA 5 - Línguas faladas pelas pessoas com quem o aluno vive

\begin{tabular}{|l|c|c|}
\hline \multicolumn{3}{|c|}{ Línguas faladas pelas pessoas com quem o aluno vive } \\
\hline \multicolumn{1}{|c|}{ Línguas } & Frequência & Percentagem (\%) \\
\hline Tétum, kemak, malaio & 8 & 18.60 \\
\hline Tétum, mambae & 7 & 16.28 \\
\hline Tétum, mambae, português & 6 & 13.95 \\
\hline Tétum, baiqueno & 5 & 11.63 \\
\hline Tétum, kemak, português & 4 & 9.30 \\
\hline Tétum, bunak & 3 & 6.98 \\
\hline Tétum, baiqueno, malaio, português & 3 & 6.98 \\
\hline Tétum, fataluco, português & 2 & 4.65 \\
\hline Tétum, tocodede, inglês & 2 & 4.65 \\
\hline Tétum, mambae, malaio, inglês & 2 & 4.65 \\
\hline Tétum, bunak, malaio, português & 1 & 2.33 \\
\hline Total & $\mathbf{4 3}$ & $\mathbf{1 0 0}$ \\
\hline
\end{tabular}

GRÁFICO 5 - Línguas faladas pelas pessoas com quem o aluno vive

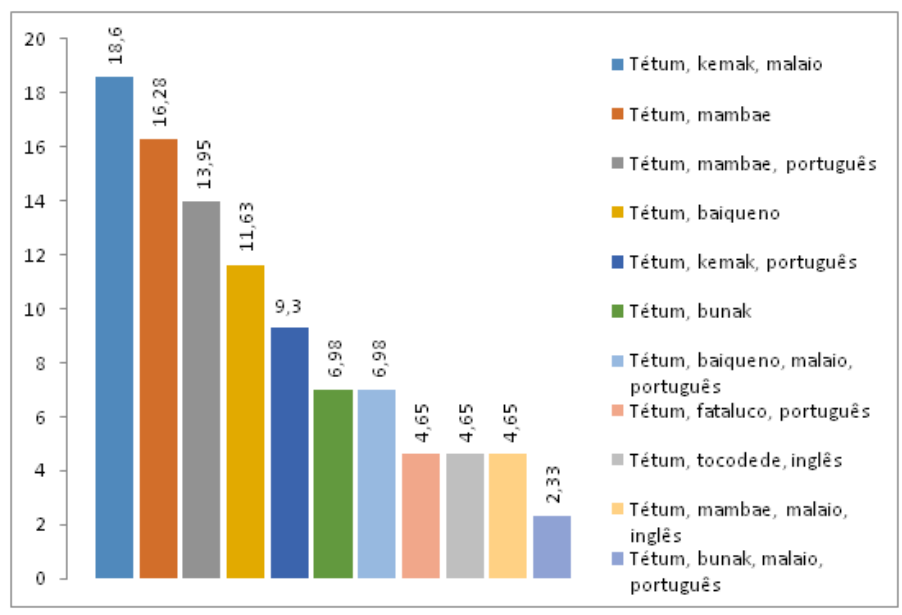




\section{Discussão}

5.1. Pela observação da Tabela 1 e do Gráfico 1, confirma-se, antes de mais, que os inquiridos assumem como LM uma diversidade de línguas (nove línguas diferentes), sendo as LM mais dominadas nas duas turmas o mambae e o kemak. Entre os 43 alunos, há dez alunos que indicaram duas LM (bunak e kemak, tétum térik e tétum, ${ }^{6}$ tocodede e baiqueno, tétum e fataluco).

Sendo os informantes estudantes que vivem em Díli, estas respostas são um pouco surpreendentes, já que a territorialidade do mapa linguístico sugere que eles deviam assumir dominantemente o tétum como LM. Naturalmente, não se pode ignorar que a capital timorense é um polo de atração de populações oriundas dos vários municípios e que, eventualmente, alguns poderão ter origens nesses municípios - e, portanto, nesses cenários linguísticos.

Ainda assim, é francamente inesperado que só dois alunos indiquem possuir o tétum como LM (e ambos em conjunto com outra língua). Por outro lado, era esperado que nenhum indicasse possuir a língua portuguesa como LM, como se confirmou.

Além disso, é igualmente surpreendente que cinco informantes $(11,63 \%)$ tenham indicado possuir duas línguas maternas. Este facto sugere que os pais (ou outros ascendentes) destes alunos têm diferentes LM e que eles as assumem igualmente como suas LM.

5.2. Baseando-nos nos resultados apresentados na Tabela 2 e no Gráfico 2 , podemos afirmar que 15 (34,88\%, mais de um terço do total) informantes nasceram no município de Díli e que 28 (60,46\%) vieram de diferentes municípios (provavelmente) para estudar na capital.

Estes resultados devem ser considerados em conjunto com as respostas à pergunta anterior, sobre as LM dos inquiridos. Neste quadro, a resposta à pergunta 2 sugere que 15 estudantes deveriam ter indicado possuir o tétum como LM. Porém, somente dois o fizeram, e associando o tétum a outra LM. Tal resposta sugere que os inquiridos associam o conceito

\footnotetext{
${ }^{6}$ Entenda-se "tétum" como a referência ao tétum praça, por oposição ao tétum térik.
} 
de LM àquela que é dominada pelos pais ou outros ascendentes, mais do que à língua comummente falada na sua área de nascimento (possibilidade corroborada pelo facto de cinco alunos terem declarado possuir duas LM); e que quase todos pertencem a famílias originárias de outras regiões de Timor-Leste.

Esta observação apresenta igualmente uma sugestão de reflexão sobre a territorialidade ou a delimitação geográfica tradicionalmente associada ao multilinguismo timorense. Ainda que o nascimento num dado ponto do território imponha um ambiente linguístico propício à aquisição de uma determinada LM, a tradição linguística familiar parece ter prevalência na identificação dos indivíduos com a sua língua.

Há que sublinhar que este estudo foi desenvolvido em Díli, espaço de confluência de timorenses de todo o país. Assim, é de esperar que o cenário acima apresentado não se repita, com os mesmos contornos, noutros locais. A este propósito, num estudo sobre o ambiente linguístico de Díli, Taylor-Leech (2012) sublinha que a capital timorense apresenta um gritante contraste com o resto do país a vários níveis, nomeadamente ao nível linguístico, e que, por isso, esta cidade não pode ser tomada como representativa do todo nacional.

De qualquer modo, esta observação, se for minimamente evocativa do cenário geral de Timor-Leste, deve fazer os linguistas repensarem a correlação linear entre território e LM, pelo menos no que respeita às perceções dos falantes. Aparentemente, o tétum não é facilmente entendido como LM, tendo este conceito contornos mais restritos do que habitualmente surge na bibliografia relevante.

5.3. Os informantes deste estudo possuem idades compreendidas entre os 15 e os 18 anos e são alunos do $11 .^{\circ}$ ano de escolaridade. Pela observação da Tabela 3 e do Gráfico respetivo, verifica-se que há 10 alunos que vivem em Díli há, pelo menos, 16 anos. Isso sugere que os restantes 33 alunos terão nascido fora da capital e terão vindo morar em Díli algum tempo ou alguns anos após o nascimento. O maior número concentra-se nos 11 anos, o que pode ser coincidente como o início da escolaridade.

Contudo, lembre-se que 15 alunos afirmaram ter nascido no município de Díli, onde a LM é tradicionalmente o tétum (ver TABELA 2). Provavelmente, terão nascido no município, mas fora da capital, tendo-se 
deslocado para a cidade mais tarde. Nesse caso, seria esperável que a sua LM fosse também o tétum, mas não é isso que os resultados mostram, já que somente dois informantes indicam esta língua como sua LM (ver TABELA 1).

5.4. As respostas à questão "Com quem vive?", cujos resultados são sintetizados na Tabela 4 e no Gráfico respetivo, são coerentes com as respostas às perguntas anteriores. Somente 10 dos 43 alunos vivem com ascendentes diretos (pais e/ou avós), o que é compatível com o facto de muitos terem nascido fora de Díli e, de acordo com a tradição timorense, terem sido deslocados para a capital para estudar, vivendo com outros familiares. Esta circunstância permite compreender mais facilmente o multilinguismo dos inquiridos e o facto de apontarem diversas línguas maternas.

Sublinhe-se que esta é uma realidade comum em Timor-Leste. Dada a inexistência de escolas (nomeadamente, escolas secundárias) em muitas localidades, é frequente encontrar-se jovens que, tendo nascido fora da capital, tenham, em determinado momento das suas vidas, acabado por se deslocar para Díli para iniciarem ou prosseguirem estudos, ficando alojados juntamente com familiares mais ou menos próximos e até amigos da família.

Há também que considerar que a designação "irmão" nem sempre indica literalmente um familiar, mas pode referir um amigo próximo.

5.5. Depois de ter observados os dados apresentados na Tabela 5 e no Gráfico 5, sobre as línguas faladas no grupo familiar com o qual o aluno vive, pode dizer-se que, no ambiente familiar próximo dos inquiridos, se falam várias línguas (no mínimo, duas; em mais de 65\% das famílias fala-se três ou mais línguas). Em todos os casos, o tétum está presente.

Assim, apesar de ser sentido como LM de somente dois informantes, o tétum está fortemente presente na vida destes estudantes.

A ecologia linguística destes indivíduos é, contudo, muito complexa, pois vivem em contextos fortemente diversificados do ponto de vista linguístico, recebendo inputs quotidianos com diferentes origens.

Em vários casos, o português está igualmente presente, com $37,21 \%$ dos informantes a identificarem esta língua entre as que são faladas na sua família. Naturalmente, os alunos que têm familiares que falam português 
podem gozar de um maior contacto com essa língua do que os outros, cujas famílias não a falam, e é naturalmente esperado que possam surgir melhores resultados escolares na disciplina de Língua Portuguesa (e em outras) entre os que podem manter esse contacto. Da mesma forma, será esperável que o tétum sofra influências do português, uma língua com a qual partilha uma larga fração do seu vocabulário.

\section{Conclusões}

É sobejamente conhecida a complexidade da ecologia linguística em Timor-Leste. Contudo, de uma forma geral, é aceite sem restrições significativas uma correlação mais ou menos linear entre língua e área geográfica. O mapa das línguas timorenses apresentado (FIGURA 2) é construído sobre esta lógica, como são habitualmente construídos mapas com objetivos semelhantes.

O presente estudo, ainda que muito limitado, vem alertar para a eventual necessidade de matizar esta afirmação, no que respeita às línguas maternas, em particular em tempos recentes, numa área geográfica que constitui um polo de atração forte para cidadãos de todo o país e que se diferencia deste por motivos diversos. Não se trata de reconhecer que o ambiente linguistico (CALVET, 2007), ou linguistic landscape (SHOHAMY; GORTER, 2009) da capital de Timor-Leste é diverso; ou ainda que o cenário linguístico timorense foi e é marcado por fronteiras porosas entre as línguas (SEVERO, 2011); essas seriam afirmações óbvias e frequentemente repetidas. Também não se trata de questionar o uso transversal do tétum nos espaços públicos e privados na cidade, convivendo com outras línguas, presentes mas menos representadas - o estudo atesta a presença do tétum nos ambientes familiares de todos os inquiridos. Trata-se de refletir, a partir de estudo complementar e muito mais alargado do que o presente, sobre a possibilidade de afirmar categoricamente que em Díli a língua materna dos cidadãos é o tétum, como correntemente vem sendo feito.

Por outro lado, pode haver a necessidade de esclarecer o conceito de LM para a generalidade dos cidadãos, já que estes (ou, em rigor, os inquiridos no presente estudo) não parecem aceitar que o tétum, língua cooficial ao lado do português, possa ser incluída nesse conceito. É comum em TimorLeste os cidadãos referirem-se às diversas línguas como LM, mas talvez não tão facilmente ao tétum, habitualmente referido como língua nacional. 
O tétum parece perder, assim, a possibilidade de ser entendido como LM, afastando-se das restantes línguas, enquanto vai consolidando o seu estatuto de língua nacional.

A língua portuguesa, presente sobretudo através da Administração e do Ensino, faz igualmente parte da ecologia linguística timorense, mas o seu domínio é ainda restrito a circunstâncias mais ou menos institucionais. Língua de instrução, mas com pouca difusão fora dos circuitos formais, a língua portuguesa tem ainda um longo caminho a percorrer até ser adotada no uso quotidiano pelos timorenses. Ainda assim, 16 alunos afirmam que no seu contexto familiar se usa esta língua, a par de outras. Esta observação é compatível com a tradição timorense de uso de línguas maternas, o que acontecia mesmo durante o período de ocupação indonésia, com imposição do uso da bahasa indonesia (variante do malaio adotado na Indonésia):

a maioria da população entendia (entende ainda) o indonésio, devido à omnipresença indonésia (civil ou militar) que a predispunha exactamente para isso; mas não que o quotidiano da população se realizasse via bahasa indonésia. O repertório da população, mesmo da juventude, quotidianamente é na língua nacional - seja esta o Tétum-Praça ou qualquer um dos vernáculos do país. Durante a ocupação, excepto nas situações formais, o uso da língua indonésia entre os timorenses, até mesmo entre os jovens, era tido como algo estranho para a cultura (CORTE-REAL; BRITO, 2006, p. 126)

A língua portuguesa manifesta a sua presença também de outra forma: o léxico do tétum incorpora uma grande percentagem de vocábulos do português, muitos deles com ligeiras alterações fonéticas. Algumas regras morfológicas, como a pluralização, misturam-se no uso quotidiano do tétum, que adotou algumas regras diferentes. Por isso, é natural que os inquiridos sintam a língua portuguesa como próxima e a reconheçam como uma das que estão presentes no seu diversificado ambiente linguístico.

Estas observações têm implicações ao nível do ensino, nomeadamente quanto à opção por metodologias de língua segunda/língua não materna. Parece ser óbvio que, nestas circunstâncias, ensinar a língua portuguesa como se ela fosse língua materna da generalidade dos timorenses não será a melhor opção. E uma das implicações do ensino que conduza a um domínio proficiente da língua terá de passar, necessariamente, por a tornar mais presente no quotidiano dos alunos. 


\section{Agradecimentos}

Este trabalho foi financiado por Fundos Nacionais através da FCT Fundação para a Ciência e a Tecnologia no âmbito do projeto do CIEC (Centro de Investigação em Estudos da Criança da Universidade do Minho) com a referência UIDB/00317/2020.

\section{Contribuição dos autores}

Os dados apresentados neste artigo são retirados da dissertação de licenciatura (graduação) de José do Carmo, realizada em 2015 na Universidade Nacional Timor Lorosa'e, em Timor-Leste, e orientada por Rui Ramos. A redação do artigo foi realizada de forma articulada pelos dois autores.

\section{Referências}

ALBUQUERQUE, D. Elementos para o estudo da ecolinguística de Timor Leste. Dominiosde Lingu@gem. Uberlândia, v. 4, n. 1, p. 21-36, 2010.

ALBUQUERQUE, D. Peculiaridades prosódicas do português falado em Timor Leste. Revista Virtual de Estudos da Linguagem - ReVEL, [S.l.], v. 8, n. 15, p. 270-285, 2010a.

ALBUQUERQUE, D. O ensino de língua portuguesa em Timor Leste: variedades e dificuldades. Interdisciplinar - Revista de Estudos em Lingua e Literatura, São Cristóvão, v. 12, p. 31-47, 2010b.

ALBUQUERQUE, D. O Português de Timor Leste: Contribuições para o estudo de uma variedade emergente. Papia: Revista Brasileira de Estudos Crioulos e Similares, São Paulo, v. 21, n. 1, p. 65-82, 2011.

ALBUQUERQUE, D. O elemento luso-brasileiro no português de Timor-Leste. Revista Virtual de Estudos da Linguagem - ReVEL, [S.l.], v. 9, n. 17, p. 226-243, 2011 a.

ALBUQUERQUE, D. Especificidades do léxico do português em Timor-Leste. Papia: Revista Brasileira de Estudos Crioulos e Similares, São Paulo, v. 22, n. 1, p. 201 223, 2012.

ALBUQUERQUE, D. Esboço morfossintático do português falado em TimorLeste. Moderna Sprak, Estocolomo, v. 106, n. 1, p. 1-10, 2012a.

ALBUQUERQUE, D. O sistema linguístico como sistema ecológico: um estudo da gramática tétun (Timor-Leste). Cadernos de linguagem e sociedade, Brasília, v. 14, n. 1, p. 175-194, 2013. DOI: https://doi.org/10.26512/les.v14i1.22227 
ALBUQUERQUE, D. Influências das L1 nativas no português de Timor-Leste: um estudo dos marcadores verbais. Revista Signótica, Goiânia, v. 26, p. 111-121, 2014. DOI: https://doi.org/10.5216/sig.v26iesp..31407

ALBUQUERQUE, D. Os contatos linguísticos em Timor-Leste: mudanças e reestruturação gramatical. Percursos Linguísticos, Vitória, v. 5, n. 11, p. 68-90, 2015.

ALBUQUERQUE, D. Um estudo da ecologia do contato de línguas em TimorLeste. ECO-REBEL - Revista Brasileira de Ecologia e Linguagem, Brasília, v. 1, p. 81-94, $2015 \mathrm{a}$.

ALBUQUERQUE, D.; TAYLOR-LEECH, K. Política linguística para as línguas oficiais em Timor-Leste: o português e o Tétum-Praça. Revista Gragoatá, Rio de Janeiro, v. 17, n. 32, p. 153-169, 2012.

ALMEIDA, N. Lingua portuguesa em Timor-Leste. Lisboa: Lidel, 2011.

ANTUNES, R. A língua portuguesa em Timor Lorosa'e. Contributos para a sua didática. 2003. Dissertação (Mestrado) - Universidade de Aveiro, Aveiro, 2003.

BRITO, R. Temas para a compreensão do atual quadro linguístico de Timor-Leste. Ciência \& Letras, Porto Alegre, v. 48, p. 175-194, 2010.

BRITO, R. Papel do português em Timor-Leste. Agália, A Crorunha, n. 104, p. 79-99, 2011.

CALVET, L.-J. As politicas lingüistica. São Paulo: Parábola, 2007.

CARDOSO, H. Descrições portuguesas das línguas de Timor-Leste na transição dos séculos XIX e XX. Moderna Sprak, Estocolomo, v. 111, n. 1, p. 1-34, 2017.

CARMO, J. Aprendizagem da lingua portuguesa e prática discursiva quotidiana: um estudo com alunos na escola secundária geral Nicolau Lobato. 2015 Monografia (Licenciatura) - Universidade Nacional Timor Lorosa'e, Díli, 2015.

CARNEIRO, A. As políticas linguísticas e de ensino de línguas em Timor-Leste: desafios de um contexto multilingue. Filologia e Linguística Portuguesa, São Paulo, v. 12, n. 1, p. 9-25, 2010. DOI: https://doi.org/10.11606/issn.2176-9419.v12i1p9-25

CARVALHO, M. J. A. Panorama linguístico de Timor. Identidade regional, nacional e pessoal. Camões: Revista de Letras e Culturas Lusófonas, Lisboa, v. 14, p. 65-89, 2003. CAVALVANTE, M. V.; BRITO, R. Língua Portuguesa: formação docente e educação pré-escolar em contexto timorense. Perspectiva, Florianópolis, v. 34, n. 2, p. 439-461, 2016. DOI: https://doi.org/10.5007/2175-795X.2016v34n2p439 
CORTE-REAL, B.; BRITO, R. Aspectos da política linguística de Timor-Leste. Desvendando contracorrentes. In: MARTINS, M.; SOUSA, H.; CABECINHAS, R. (ed.). Comunicação e lusofonia para uma abordagem crítica da cultura e dos media. Porto: Campo das Letras, 2006. p. 123-131.

FILL, A. Language and Ecology: Ecolinguistic Perspectives for 2000 and Beyond. In: AILA'99, 1999, Tokyo. Proceedings [...]. Tokyo: AILA, 2000. p. 162-176.

FONSECA, S.; OSÓRIO, P.; SANTOS, R. Contributo para uma análise do quadro linguístico de Timor-Leste: o caso da língua portuguesa. In: OSÓRIO, P.; BERTINETTI (org.). Teorias e usos linguísticos. Aplicações ao português língua não materna. Lisboa: Lidel, 2015. p. 316-334.

GUIMARÃES, J.; COSTA, J. O ensino-aprendizagem de lingua portuguesa em TimorLeste: considerações de professores do ensino básico. In: PAULINO, V.; BARBOSA, A. (org.). Lingua, ciência e formação de professores em Timor-Leste. Díli: Programa de PósGraduação e Pesquisa da UNTL, 2016. p. 25-32. DOI: https://doi.org/10.12957/ matraga.2018.33956

HAUGEN, E. The Ecology of Language. In: FILL, A.; MÜHLHÄUSLER (ed.). The Ecolinguistics Reader. Language, Ecology and Environment. London; New York: Continuum, 2001. p. 57-66.

HULL, G. The Languages of Timor 1772-1997: A Literature Review. Studies in Languages and Cultures of East Timor, Sydney, v. 1, p. 1-38, 1998.

HULL, G. The Languages of East Timor: Some Basic Facts. Dili: Instituto Nacional de Linguística, Universidade Nacional Timor Lorosa'e, 2002.

INDART, K. Políticas de educação, políticas de língua, identidade nacional e a construção do estado em Timor-Leste. 2017 Tese (Doutorado) - Universidade do Minho, Braga, 2017.

LOURENÇO, S. Um quadro de referência para o ensino do português em Timor-Leste. Lisboa: Lidel, 2011.

RAMOS, R. Instituto da Lingua Portuguesa da Universidade Nacional Timor Lorosa'e: missão e ação. In: PAULINO, V.; BARBOSA, A. (org.). Lingua, ciência e formação de professores em Timor-Leste. Díli: Programa de Pós-Graduação e Pesquisa da UNTL, 2016. p. 65-74.

RAMOS, R. Ecolinguística: um novo paradigma para a reflexão sobre o discurso?. In: OLIVEIRA, F.; DUARTE, I. (org.). Da língua e do discurso. Porto: Campo das Letras, 2004. p. 545-562.

RAMOS, R. Linguística e ambientalismo. In: MARQUES, M. A. et al. (org.). In: ENCONTRO INTERNACIONAL DE ANÁLISE LINGUÍSTICA DO DISCURSO. PRÁTICAS DE INVESTIGAÇÃO EM ANÁLISE LINGUÍSTICA 
DO DISCURSO, II., 2000, Braga.. Actas [...]. Braga: Universidade do Minho; Centro de Estudos Humanísticos, 2004a. p. 49-62.

SEVERO, C. Questões de língua, identidade e poder: hibridismos em Timor Leste. Revista Brasileira de Linguística Aplicada, Belo Horizonte, v. 11, n. 1, p. 95-113, 2011. DOI: https://doi.org/10.1590/S1984-63982011000100006

SOARES, L. Línguas em Timor-Leste: que gestão escolar do plurilinguismo? 2014. Tese (Doutorado) - Universidade de Aveiro, Aveiro, 2014.

SHOHAMI, E.; GORTER, D. (ed.). Linguistic Landscape: Expanding the Scenery. New York; London: Routledge, 2009. DOI: https:// doi.org/10.4324/9780203930960 TAYLOR-LEECH, K. The Language Situation in Timor-Leste. Current Issues in Language Planning, Londres, v. 10, n. 1, p. 1-68, 2009. DOI: https://doi. org/10.1080/14664200802339840

TAYLOR-LEECH, K. Timor-Leste: Sustaining and Maintaining the National Languages in Education. Current Issues in Language Planning, Londres, v. 12, n. 2, p. 289-308, 2011. DOI: https://doi.org/10.1080/14664208.2011.589108

TAYLOR-LEECH, K. Language Choice as an Index of Identity: Linguistic Landscape in Dili, Timor-Leste, International Journal of Multilingualism, Londres, v. 9, n. 1, p. 15-34, 2012. DOI: https://doi.org/10.1080/14790718.2011.583654

THOMAZ, L. F. Note sur le 'Dictionnaire françois et timorien' de F.E. de Rosily. Archipel (Etudes interdisciplinaires sur le monde insulindien), Paris, vol. 23, p. 105-108, 1982.

THOMAZ, L. F. Babel Loro Sa'e. O problema linguístico de Timor-Leste. Lisboa: Instituto Camões, 2002. DOI: https://doi.org/10.3406/arch.1982.1724

VIEGAS, E.; RAMOS, R.; ANTUNES, R. Avaliação da proficiência em língua portuguesa dos docentes da Universidade Nacional Timor Lorosa'e, Timor-Leste. Indagatio Didactica, Aveiro, v. 7, n. 2, p. 58-82, 2015.

XIMENES, F. O ensino da língua portuguesa na Universidade Nacional Timor Lorosa'e: um estudo sobre o departamento de língua portuguesa. In: PAULINO, V.; BARBOSA, A. (org.). Lingua, ciência e formação de professores em Timor-Leste. Díli: Programa de Pós-Graduação e Pesquisa da UNTL, 2016. p. 43-51.

Data de recebimento: 30/03/2020. Data de aprovação: 12/09/2020. 